\title{
Size Effect on Fatigue in Bending of Concrete
}

\author{
By Jun Zhang, ${ }^{1}$ Victor C. Li, ${ }^{2}$ Fellow, ASCE, and Henrik Stang ${ }^{3}$
}

\begin{abstract}
This paper presents a semianalytical method to predict fatigue behavior in flexure of concrete in the case of maximum flexural moment larger than that of the first crack moment based on force equilibrium in the critical cracked section. The model relies on the cyclic bridging law, the so-called stress-crack-width relation under cyclic tensile load as the fundamental constitutive relationship in tension. The structural size effect on fatigue in bending of concrete beams is studied by the present model. Eight series of beams, with heights from 50 to $800 \mathrm{~mm}$, are analyzed. The model results show that the fatigue performance in bending, normally expressed in terms of the maximum flexural stress versus fatigue life diagram $(S-N)$ is strongly dependent on the structural size, even when the same material parameters are used in the model. Under the same cyclic flexural stress levels, the smaller the beam height, the longer the fatigue life is. Besides this, the deformation characteristics, such as fatigue crack growth history as well as the final fatigue crack length, are also size dependent. Finally, the model predictions are compared with experimental results. Good agreement between model predictions and experiments has been obtained.
\end{abstract}

\section{INTRODUCTION}

Interest in the fatigue of concrete arises because structures such as concrete bridges, offshore elements, and concrete pavements are loaded by cyclic forces. For example, concrete overlays for highway or bridge decks are expected to resist millions of cycles of repeated axle loads from passing traffic during their service lives. Airport pavements are subjected to a smaller number of repeated loadings during their design lives, ranging from about several thousand to several hundred thousand cycles of repeated loading. Concrete structures supporting dynamic machines are also subjected to hundreds of millions of load cycles involving complicated stress states. The fatigue performance of these structures has to be considered by researchers and designers. First, the cyclic load may cause structural fatigue failure. Second, the effects of repeated loading on the characteristics of materials (static strength, stiffness, toughness, durability, etc.) might be significant under service loading even if the load does not cause a fatigue failure. A number of studies have been made to evaluate the fatigue performance of concrete (Murdock and Kesler 1959; Tepfers 1979; Tepfers and Kutti 1979; Hsu 1981; Zhang and Phillips 1989; Zhang and Stang 1998a). The size effect of structural elements, as one of the most important consequences of fracture mechanics, has been studied both experimentally and theoretically in concrete members over the last decade in the case of monotonic load application (Bazant 1984, 1987, 1992; Li et al. 1998). However, size effect of structural elements under fatigue loading has so far received very little attention.

The main objective of the present work is to evaluate theoretically the structural size effect on fatigue in bending of concrete. A semianalytical model to predict fatigue behavior in flexure of concrete based on force equilibrium in the critical cracked section is developed. The model relies on the cyclic bridging law, the so-called stress-crack-width relation under cyclic tensile load, as the fundamental constitutive relationship in tension. Fatigue strength of concrete beams in bending, in

\footnotetext{
${ }^{1}$ Assoc. Prof., Dept. of Civ. Engrg., Tsinghua Univ., Beijing, 100084, PRC.

${ }^{2}$ Prof. and Dir., ACE-MRL, Dept. of Civ. and Envir. Engrg., Univ. of Michigan, Ann Arbor, MI 48109-2125.

${ }^{3}$ Assoc. Prof., Dept. of Struct. Engrg. and Mat., Tech. Univ. of Denmark, DK2800, Lyngby, Denmark.

Note. Associate Editor: Nemkumar Banthia. Discussion open until May 1, 2002. To extend the closing date one month, a written request must be filed with the ASCE Manager of Journals. The manuscript for this paper was submitted for review and possible publication on August 30, 1999; revised January 30, 2001. This paper is part of the Journal of Materials in Civil Engineering, Vol. 13, No. 6, November/December, 2001. (C)ASCE, ISSN 0899-1561/01/0006-0446-0453/\$8.00 + \$.50 per page. Paper No. 21786.
}

terms of maximum flexural-stress-fatigue-life diagrams $(S$ $N)$, is obtained.

Although the well-known empirical Paris Law (Paris and Erdogan 1963) has been applied to the study of concrete fatigue crack growth (Bazant and Xu 1991; Bazant and Schell 1993), the fact that concrete typically exhibits nonlinear fracture processes because of the large process zone makes this linear elastic fracture mechanics (LEFM)-based approach questionable. Instead, the present work provides a model based on physical principles, which embodies the experimentally observed bridging degradation across a concrete crack under repeated tensile loading. When incorporated into a nonlinear crack growth analysis, this model reproduces remarkably well the macroscopic fatigue behavior of concrete beams under cyclic loading.

In the following, the fatigue model is first introduced. The results of numerical analyses of fatigue crack growth in concrete beams with various heights are presented and discussed. Model predictions are compared with experimental results. Conclusions on size effect of concrete beams under cyclic loading are drawn at the end of the paper.

\section{FATIGUE MODEL}

\section{Mechanism of Fatigue Crack Growth in Concrete}

Normally, it can be said that fatigue is a process of progressive, permanent internal structural changes occurring in a material subjected to repetitive stress. The progressive fatigue damage on material constituents is responsible for fatigue life of a material. For plain concrete, the material phases can broadly be classified as cement paste and aggregates, as well as the interfaces between aggregate and hydrated cement paste. The fatigue loading causes these physical phases to undergo microscopic changes, such as opening and growth of bond cracks, which exist at the interfaces between coarse aggregate and hydrated cement paste even prior to the application of load (Neville and Brooks 1987), reversed movement of aggregates along the interface, aggregate surface abrasion, and damage of the interface under repeated load. These microscopic changes in turn cause detrimental changes in macroscopic material properties. Typically, the aggregate bridging force decreases with number of cycles because of the interfacial damage or aggregate breakage (Zhang et al. 2000). So it can be said that fatigue damage to interfaces of aggregate/matrix, which are generally the weakest phase in concrete, as well as to soft aggregates, results in aggregate bridging stress degradation and leads to fatigue crack growth in concrete. On the other hand, fatigue life of concrete structures is controlled by fatigue crack growth behavior. 
The fatigue crack growth process in concrete can be divided broadly into two stages: the crack initiation period and the development period. Consider a simply supported rectangular beam loaded in bending fatigue load with constant amplitude between maximum and minimum moment $M_{\max }$ and $M_{\min }$. When $M_{\max }<M_{f c}$, where $M_{f c}$ is the first crack moment, the fatigue life of the beam can be given by

$$
N_{t}=N_{c i}+N_{c g}
$$

When $M_{\max } \geq M_{f c}$, the fatigue life is

$$
N_{t}=N_{c g}
$$

where $N_{t}=$ total fatigue life; and $N_{c i}$ and $N_{c g}=$ fatigue life component for the crack initiation and growth, respectively (Fig. 1). The first term $N_{c i}$ is dependent on the microcracking in the material, which is highly influenced by the microstructure of the concrete matrix, such as the water/cement ratio, aggregate properties as well as pore structure, size distribution, and content. The second term $N_{c g}$ is strongly dependent on the bridging performance within the fracture zone under fatigue loading.

This paper focuses on the fatigue life prediction of $N_{c g}$; i.e., the case where maximum bending moment $M_{\max }$ is larger than the first crack bending moment $M_{f c}$. Based on the above discussions, some assumptions for fatigue modeling of $N_{c g}$ can be stated:

- After a dominant fatigue crack is created, the bridging behavior within the fracture zone governs the rate of fatigue crack advancement.

- The stress at the crack tip remains constant and is equal to the material tensile strength.

- Material properties outside the fracture zone are unchanged during fatigue loading.

It is further assumed that the concrete essentially shows a linear response in tension up to peak load. After peak load, one discrete crack is formed. The discrete crack formation is described by the crack bridging law (or stress-crack-width relationship) under both monotonic and cyclic loading. Thus the following material parameters are fundamental in the constitutive relations of concrete in tension fatigue: Young's modulus $E$, tensile strength $\sigma_{t}$, and cyclic-stress-crack-width $(\sigma$ $w, N)$ relationship. In compression the behavior of concrete and fiber-reinforced concrete materials is assumed to be linear
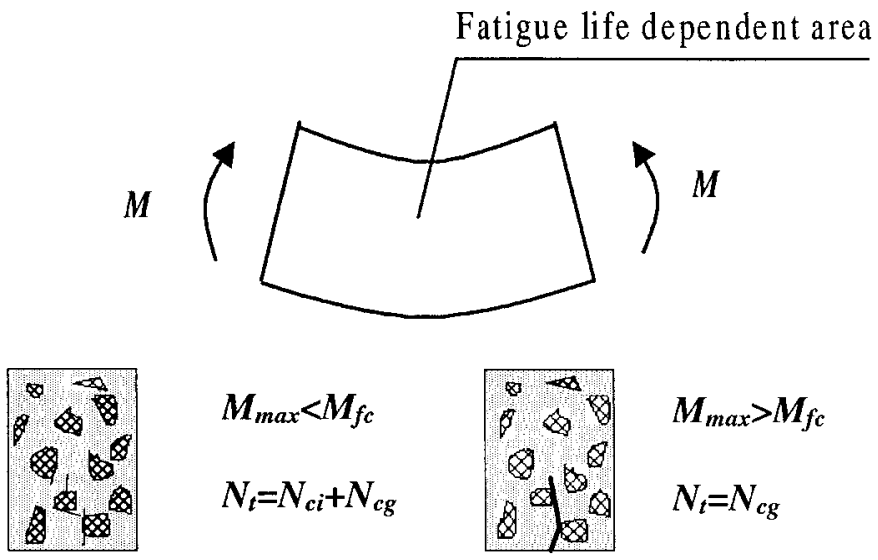

$$
M_{m a x}>M_{f c}
$$$$
N_{t}=N_{c g}
$$

$\$$

Coarse aggregate

- Microcracks

- Dominant macrocrack

FIG. 1. Fatigue Life Components in Bending
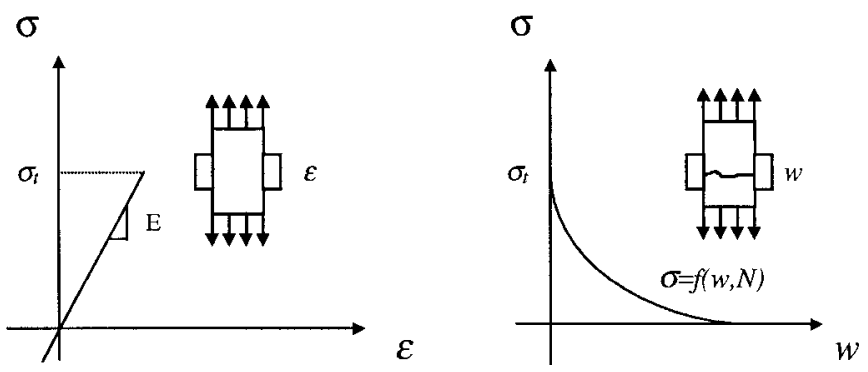

FIG. 2. Constitutive Law of Concrete in Tension Fatigue

elastic and the Young's modulus in compression is the same as in tension. The mechanical behavior of concrete in tension fatigue is summarized in Fig. 2.

\section{Bridging Model of Concrete under Tension Fatigue}

\section{Monotonic Tension}

Crack bridging in concrete is mainly provided by fine aggregate bridging and coarse aggregate bridging, which are generally governed by the characteristics of aggregates, such as the grading, maximum particle size, and surface texture (smooth or rough). The detailed physics of aggregate bridging in concrete have not been fully understood and a model based on the mechanism of this bridging action is not available at present. Some empirical models of aggregate bridging have been proposed in recent years (Hordijk 1992; Stang 1992). In the present investigation, an empirical model proposed by Stang (1992) will be adopted. In this model the aggregate bridging stress $\sigma$ is expressed as a function of the crack width $w$

$$
\sigma=\frac{\sigma_{t}}{1+\left(w / w_{0}\right)^{p}}
$$

where $\sigma_{t}=$ maximum bridging stress due to aggregate action at $w=0$, which is equal to the tensile strength of material; $w_{0}$ corresponds to the crack opening when the stress has dropped to half of $\sigma_{t}$; and $p=$ shape factor. It has been shown that the aggregate bridging model given by (3) with $p=1.2$ and $w_{0}=$ $0.015 \mathrm{~mm}$ fits a wide range of experimental data extremely well, including normal and high-strength concrete.

\section{Cyclic Tension}

Degradation of aggregate bridging of concrete under cyclic uniaxial tension had been found by Gopalaratnam and Shah (1985), Reinhardt et al. (1986), and Hordijk (1992) and further investigated by Zhang et al. (1999, 2000). By analyzing the experimental data, it is concluded that degradation of crack bridging under cyclic load is controlled by the number of cycles and the maximum and minimum crack openings. From a large number of experimental data of uniaxial fatigue tension tests on a precracked steel fiber-reinforced concrete specimen, it was shown that the cyclic crack-bridging law of fiber-reinforced concrete at maximum crack width level $w_{\max }$ can be fitted by a linear model as a function of the logarithm of the number of cycles (Zhang et al. 1999, 2000). The slope reflects the influence of the amplitude of the crack opening during fatigue loading. The aggregate bridging degradation is included as well as the fiber bridging degradation. For plain concrete, one assumes that the described law can still be applied. The cyclic aggregate bridging law can then be fitted by

$$
\begin{gathered}
\frac{\sigma_{N}}{\sigma_{1}}=1-d \log (N) \quad \text { for } d \log (N)<1 \\
\frac{\sigma_{N}}{\sigma_{1}}=0 \quad \text { for } d \log (N) \geq 1
\end{gathered}
$$


where $\sigma_{N}$ and $\sigma_{1}$ denote bridging stress at the $N$ th cycle and first cycle, respectively; $\sigma_{1}$ is given by (3); and $d=$ stress degradation factor, which reflects the rate of aggregate bridging degradation and is a function of maximum and minimum crack openings during fatigue loading. As the minimum crack width corresponding to the zero load, $d$ can be approximately related to the maximum crack width $w_{\max }$ by

$$
d=d_{0}+\gamma w_{\max }
$$

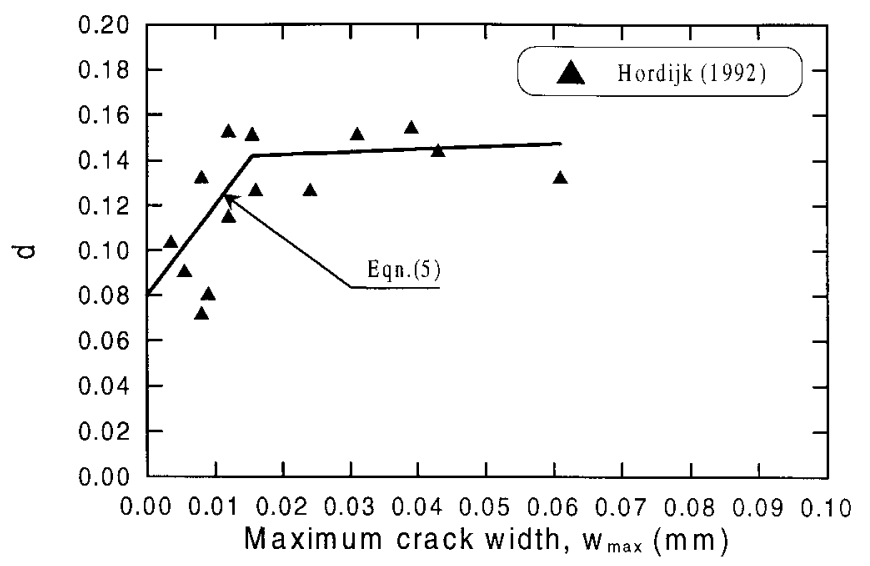

FIG. 3. Aggregate Degradation Coefficient $d$ as Function of Maximum Crack Width

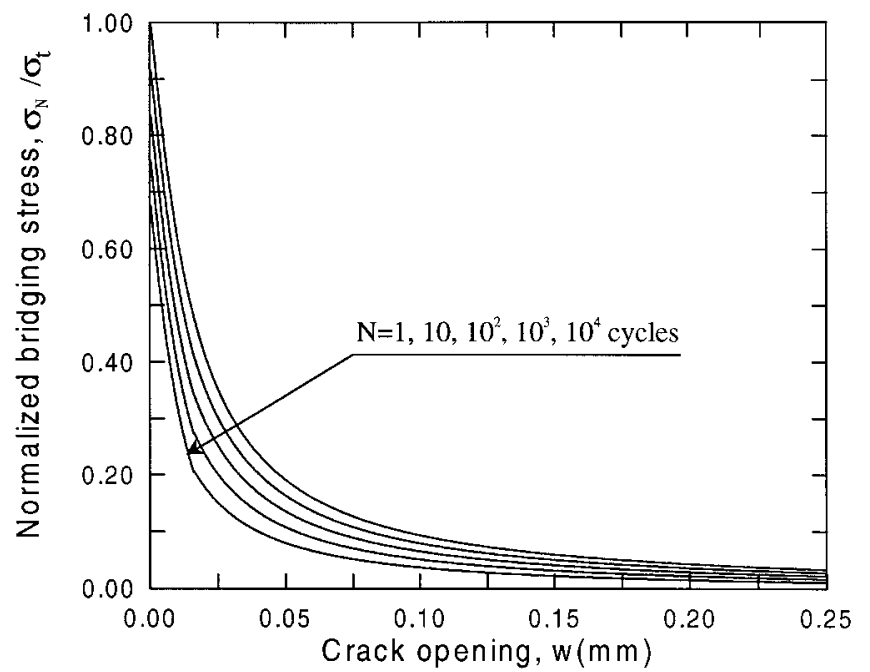

FIG. 4. Stress-Crack-Width Relationship after Undergoing Different Number of Cycles where $d_{0}=$ stress degradation factor at $w_{\max }=0$; and $\gamma=$ slope of the linear relation between the bridging degradation factor $d$ and maximum crack width $w_{\max }$. Through analysis of experimental results of concrete under cyclic uniaxial tensile tests (Hordijk 1992), it is found that, when $d_{0}=0.08$ and $\gamma=$ $4 \mathrm{~mm}^{-1}$ for $w_{\max } \leq 0.016 \mathrm{~mm}$ and when $d_{0}=0.14$ and $\gamma=$ $0.12 \mathrm{~mm}^{-1}$ for $w_{\max }>0.016 \mathrm{~mm}$, the model predictions can fit the test results well. The comparison between (5) and test results is shown in Fig. 3. Fig. 4 shows the cyclic bridging law of concrete given by (4). The figure shows the bridging stress as a function of crack width after undergoing a certain number of cycles.

\section{Prediction of Fatigue Crack Growth in Concrete Beams under Bending Load}

In recent years, a number of fictitious crack analytical models (Hillerborg et al. 1976) for predicting the structural behavior of concrete and fiber-reinforced concrete beams under bending load have been developed. Maalej and Li (1994) developed an analytical model of a fiber-reinforced concrete beam in bending based on the equilibrium of forces in the critical cracked section. Ulkjær et al. (1995) developed an analytical model for plain concrete beams in bending based on plastic hinge analysis, which assumes development of a fictitious crack in an elastic layer with a thickness proportional to the beam depth. A linear tension softening relation is assumed. In this paper, an analytical bending model based on the equilibrium of forces in the critical cracked section with a power function softening relation (Stang 1992) for fatigue analysis of plain concrete will be developed.

Consider a short segment of a simply supported rectangular beam with width $B$, depth $H$, and span $L$ that is subjected to an external bending moment $M$. The behavior of the beam is assumed to be elastic until the maximum principle tensile stress reaches the tensile strength of the material. After that it is assumed that a single crack is formed with a maximum tensile strength at the crack tip. The moment corresponding to the initiation of the fictitious crack is the so-called first crack moment $M_{f c}$ corresponding to the first crack load $P_{f c}$, when the moment is transformed into force load. Thus the failure process of a beam can be divided into two stages: linear elastic and fictitious crack developing. The assumed stress distribution in the second stage is shown in Fig. 5, where the crack tip is defined at a crack width equal to zero $(w=0)$.

At the end of the first stage, according to classical elastic theory, one has

$$
M_{f c}=\frac{B H^{2}}{6} \sigma_{t}
$$

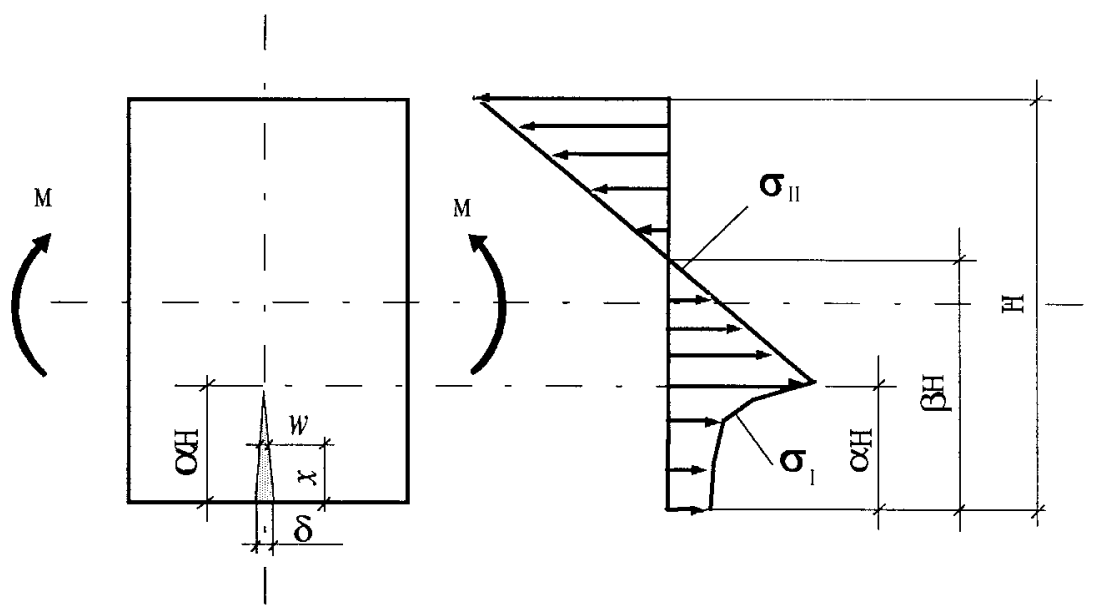

FIG. 5. Distribution of Normal Stress in Critical Cracked Section 
where $\sigma_{t}=$ tensile strength of the material.

In the second stage, the crack length $\alpha H, \alpha \in[0,1]$, crackmouth opening displacement (CMOD) $\delta$, and external moment $M$ can be related through the analysis shown below. First one assumes that the crack has a linear crack opening profile, then

$$
w=\delta\left(1-\frac{x}{\alpha H}\right)
$$

where $w=$ crack width at location $x$; and $\delta=$ width at the crack mouth (Fig. 5). Next from equilibrium conditions, one has

$$
\begin{gathered}
\int_{0}^{\alpha H} \sigma_{I}(x) d x+\int_{\alpha H}^{H} \sigma_{I I}(x) d x=0 \\
\int_{0}^{\alpha H} \sigma_{I}(x)(H-x) B d x+\int_{\alpha H}^{H} \sigma_{I I}(x)(H-x) B d x=M
\end{gathered}
$$

where $M=P L / 4$ for the three-point bending case ( $P=$ external load); and $\sigma_{I}(x)$ and $\sigma_{I I}(x)=$ normal stress functions in the cracked and uncracked parts, respectively $-\sigma_{I}(x)$ can be related to $\alpha h$ and $\delta$ through the stress-crack-width relationship together with (7)

$$
\sigma_{I}(x)=\sigma(w)=\sigma\left(\delta\left(1-\frac{x}{\alpha H}\right)\right)
$$

From the assumed stress distribution at the uncracked part, $\sigma_{I I}(x)$ can be related to $\alpha H, \beta H$, and $\delta$ by

$$
\sigma_{I I}(x)=\sigma_{t}\left(1-\frac{x-\alpha H}{\beta H-\alpha H}\right)
$$

where $\beta H=$ depth of the tensile zone, $\beta \in[0.5,1]$. To obtain the complete solution of external load and CMOD for a given crack length, another relationship between them is necessary. According to the principle of superposition, the CMOD under bending load can be decomposed

$$
\delta=\delta_{M}+\delta_{\sigma_{I}(x)}
$$

where $\delta_{M}$ and $\delta_{\sigma_{I}(x)}=$ CMOD components caused by an external moment $M$ on an unbridged cracked beam and due to bridging stress $\sigma_{I}(x)$, respectively $-\delta_{\sigma_{I}(x)}$ can be obtained through simplifying $\sigma_{I}(x)$ as a cracked beam with crack length $\alpha H$ and subjected to moment $M^{\prime}$ and axial stress $\sigma^{\prime}$. Then

$$
\delta_{\sigma_{I}(x)}=\delta_{M^{\prime}}+\delta_{\sigma^{\prime}}
$$

where $M^{\prime}$ and $\sigma^{\prime}$ are given by

$$
\begin{gathered}
M^{\prime}=\int_{0}^{\alpha H} \sigma_{I}(x)\left(\frac{H}{2}-x\right) B d x \\
\sigma^{\prime}=\frac{1}{H} \int_{0}^{\alpha H} \sigma_{I}(x) d x
\end{gathered}
$$

According to Tada (1985), the total CMOD can be expressed

$$
\delta=\frac{24 \alpha}{B H E}\left[M V_{1}(\alpha)-M^{\prime} V_{2}(\alpha)\right]-\frac{4 \sigma^{\prime} \alpha H}{E} V_{3}(\alpha)
$$

where, under three-point bending load

$$
\begin{gathered}
V_{1}(\alpha)=0.33-1.42 \alpha+3.87 \alpha^{2}-2.04 \alpha^{3}+\frac{0.66}{(1-\alpha)^{2}} \\
V_{2}(\alpha)=0.8-1.7 \alpha+2.4 \alpha^{2}+\frac{0.66}{(1-\alpha)^{2}} \\
V_{3}(\alpha)=\frac{1.46+3.42\left(1-\cos \frac{\pi \alpha}{2}\right)}{\left(\cos \frac{\pi \alpha}{2}\right)^{2}}
\end{gathered}
$$

where $E=$ elastic modulus of material; and $V_{1}(\alpha)$ is slightly changed from Tada's function after comparing with the finiteelement implementation of Zhang and Stang (1998b).

According to the basic assumptions given above, as a first approximation, the fatigue analysis can be carried out by replacing the bridging stress in the fracture zone $\sigma_{I}(x)$ with the cycle dependent models given by (4). The determination of fatigue crack length and crack mouth opening corresponding to certain cycles for a given fatigue loading procedure is performed according to the following algorithm.

For a given maximum and minimum load level $M_{\max }$ and $M_{\text {min }}$ (here only the case of $M_{\max }>M_{f c}$ is considered), in the first cycle, the crack length and crack mouth opening are determined by solving the nonlinear (8), (9), and (16) through a simple bisection iteration scheme. The bridging law without stress degradation $(N=1)$ will be used as the input for $\sigma_{I}(x)$, and a numerical integration method is employed. In the second cycle $(N=2)$, because the fatigue crack undergoes a closing and opening procedure, bridging degradation will occur in the fracture zone. The load capacity $M$ cannot reach $M_{\max }$ with the already formed crack area when this crack opens to the previous maximum width. Therefore, a new crack area is needed to reach the maximum load level. The bridging laws with $N$ $=2$ and $N=1$ will be used in the old fracture zone and the newly developed fracture zone, respectively. Solving (8), (9), and (16) again, the new developed crack length $\Delta a_{2}$ and crack mouth opening $\delta$ can be obtained. Through similar repeated calculations, one can get all the new developed crack length $\Delta a_{3}, \Delta a_{4}, \Delta a_{5}, \ldots$ and corresponding crack mouth openings at cycle $N=3,4,5, \ldots$. This procedure will be continued until the load capacity starts to drop with increasing crack length. At this stage, the beam is considered to have failed in fatigue. According to this procedure, for the $N$ th load cycle, the fracture zone will be divided into $N$ sections with different fatigue history, ranging from 1 to $N$ cycles. To speed up the calculation procedure, increments with $>1$ cycle can be used, normally 5 to 10 or 20 cycles. This depends on the load level, fatigue crack growth rate, and required accuracy. In this case, a linear interpolation of crack length in one increment has been used.

\section{NUMERICAL ANALYSES AND DISCUSSIONS}

To investigate the size effect on fatigue in bending, a series of concrete beams with height 50,100, 150, 200, 300, 400, 500 , and $800 \mathrm{~mm}$ are simulated under fatigue bending load with the above model. Constant amplitude between maximum and minimum flexural load is adopted. As an example, a specific fatigue loading procedure with minimum flexural load equal to zero is assumed in the numerical calculation. The material parameters used in the model are listed in Table 1.

\section{S-N Curves}

Fatigue strength is commonly defined as a stress level, either in absolute or in normalized form, which can be supported repeatedly for a given number of cycles. It can be represented

TABLE 1. Material Parameter Values Used in Model

\begin{tabular}{ll}
\hline \hline Parameter & \multicolumn{1}{c}{ Value } \\
\hline$E(\mathrm{GPa})$ & 30 \\
$\sigma_{t}(\mathrm{MPa})$ & 5.2 \\
$\sigma_{c}(\mathrm{MPa})$ & 53.22 \\
$p$ & 1.2 \\
$w_{0}(\mathrm{~mm})$ & 0.015 \\
$d_{0}$ & $0.08\left(\right.$ for $\left.w_{\max } \leq 0.016 \mathrm{~mm}\right)$ \\
& $0.14\left(\right.$ for $\left.w_{\max }>0.016 \mathrm{~mm}\right)$ \\
$\gamma\left(\mathrm{mm}^{-1}\right)$ & $4\left(\right.$ for $\left.w_{\max } \leq 0.016 \mathrm{~mm}\right)$ \\
& $0.12\left(\right.$ for $\left.w_{\max }>0.016 \mathrm{~mm}\right)$ \\
\hline \hline
\end{tabular}


by stress-fatigue-life curves, normally referred to as $S-N$ curves. In the case of fatigue in bending, $S$ refers to the flexural stress according to classical elastic theory.

To compare the results between monotonic and fatigue loadings, the monotonic bending behavior is simulated first in terms of the flexural stress and deformation (CMOD and crack length) relation. Fig. 6 shows the monotonic flexural stress versus normalized crack length curves of concrete beams with different heights. The flexural stress versus CMOD diagram is shown in Fig. 7.

On inspecting the numerical results shown in Figs. 6 and 7, several features of the concrete beam under bending load can be distinguished:

- Load level one is when the flexure stress increases linearly with deformation up to tensile strength of the material, 5.2 MPa. In this stage, material behavior obeys elastic constitutive relations and no fictitious crack is formed; therefore, CMOD is equal to zero.

- Load level two is when the flexural stress increases up to flexural strength, called the modulus of rupture (MOR). In this period, the deformation increases little more than proportionally with respect to the stress. A fictitious crack develops at the midlength of the beam and grows with

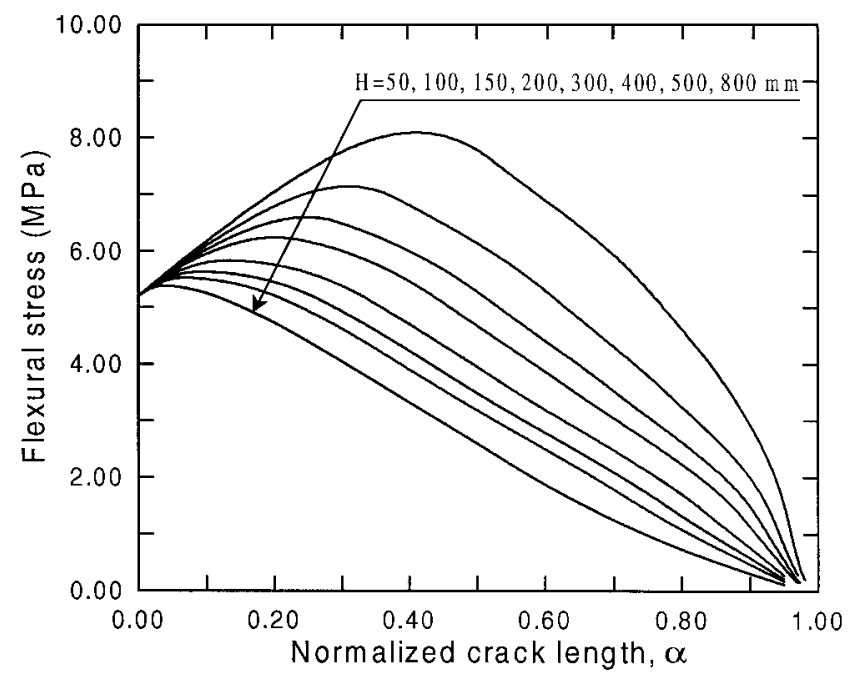

FIG. 6. Flexural Stress versus Normalized Crack Length Diagrams of Concrete Beams under Monotonic Bending Load; Effect of Beam Height Is Shown

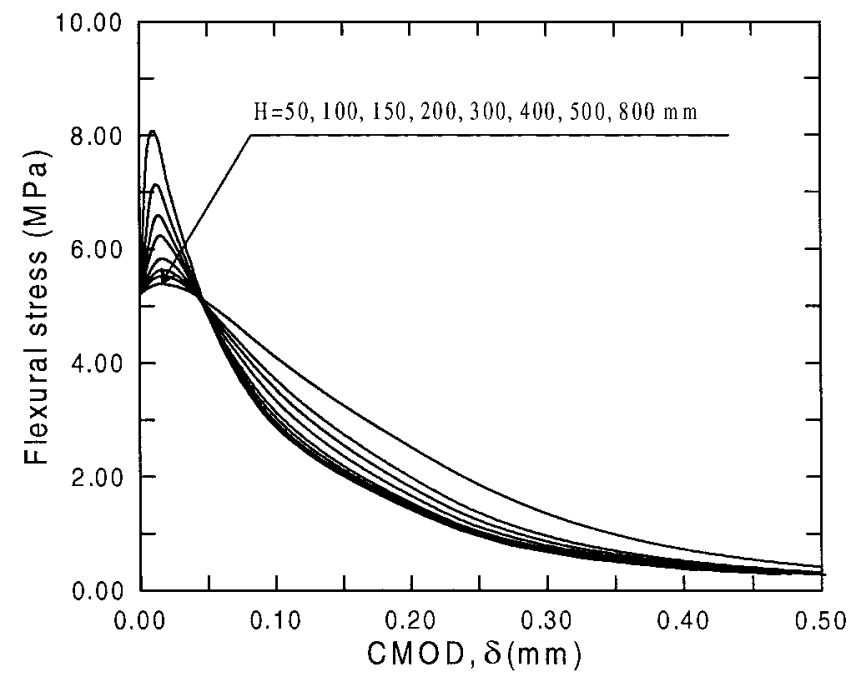

FIG. 7. Flexural Stress versus CMOD Diagrams of Concrete Beams under Monotonic Bending Load; Effect of Beam Height Is Shown the load increasing. The ratio between stress and displacement, the so-called stiffness of beam $(d \sigma / d \delta)$ is size dependent.

- In addition to the well-known size dependence in flexural strength (MOR), the critical crack length $a_{c}$ and critical crack mouth opening $\delta_{c}$, defined as the CMOD when MOR is reached, are size dependent also. The quantity of $a_{c}$ sometimes is very important if a simplified load-carrying capacity design method is to be used, which is usually based on the stress distribution along the critical cross section of a concrete beam (i.e., a critical crack length at failure is assumed).

Plotted in Fig. 8, is the normalized critical crack length and critical crack mouth opening versus beam height curves. It is obvious that both critical crack length and critical crack mouth opening are strongly dependent on the structural size. Attention needs to be taken in any design practice with regard to this aspect.

Fig. 9 shows the relation between maximum flexural stress and fatigue life, the so-called $S-N$ curves for concrete beams with different heights. First, the $S$ - $\log (N)$ curve of concrete is almost linear, which agrees with a number of experimental observations (Murdock and Kesler 1959; Tepfers 1979; Tepfers and Kutti 1979; Hus 1981; Zhang and Phillips 1989; Zhang and Stang 1998a). Second, the $S$ - $N$ curve of concrete under bending load is size dependent; i.e., for a given maximum flexural load level, different fatigue life can be obtained for different beam size. The larger the beam height, the shorter is the fatigue life under the same maximum flexural stress. Here, the case of maximum flexural stress larger than the first

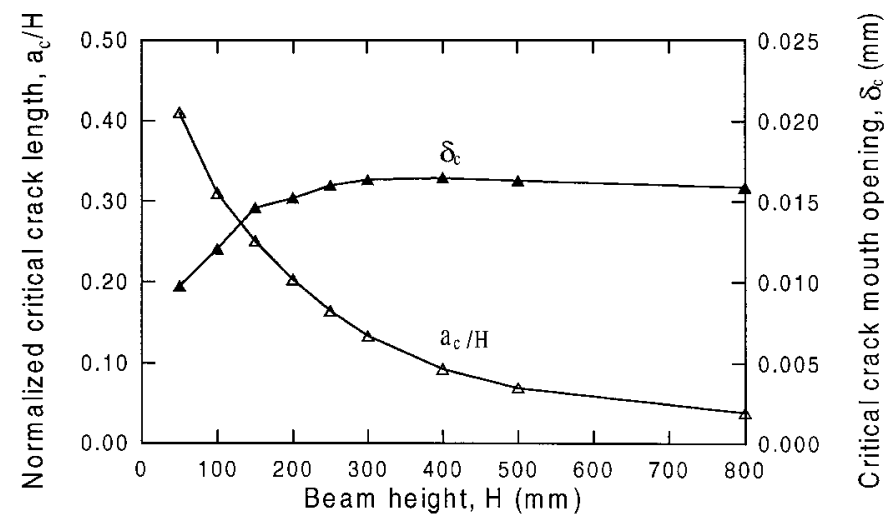

FIG. 8. Effect of Beam Size on Critical Crack Length and Critical CMOD for Monotonic Loading

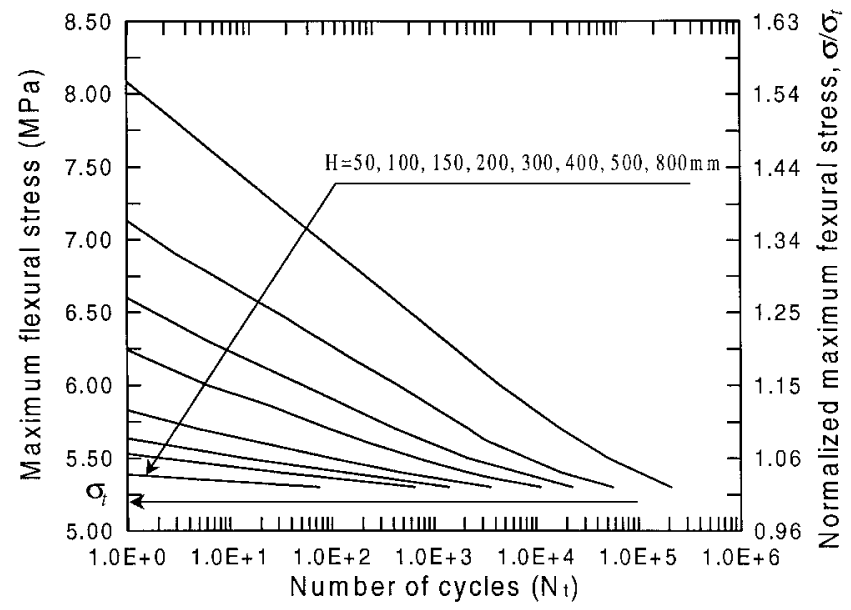

FIG. 9. Relation of Maximum Flexure Stress with Fatigue Life, Showing Effect of Beam Size 
crack strength of concrete is simulated only. For example, as the maximum and minimum flexural stresses are equal to 5.3 $\mathrm{MPa}$ and zero, respectively, for beams with heights from 50 to $800 \mathrm{~mm}$, the fatigue life changes from $10^{5}$ to $10^{2}$ cycles. The reason for this size dependence in fatigue is a combination

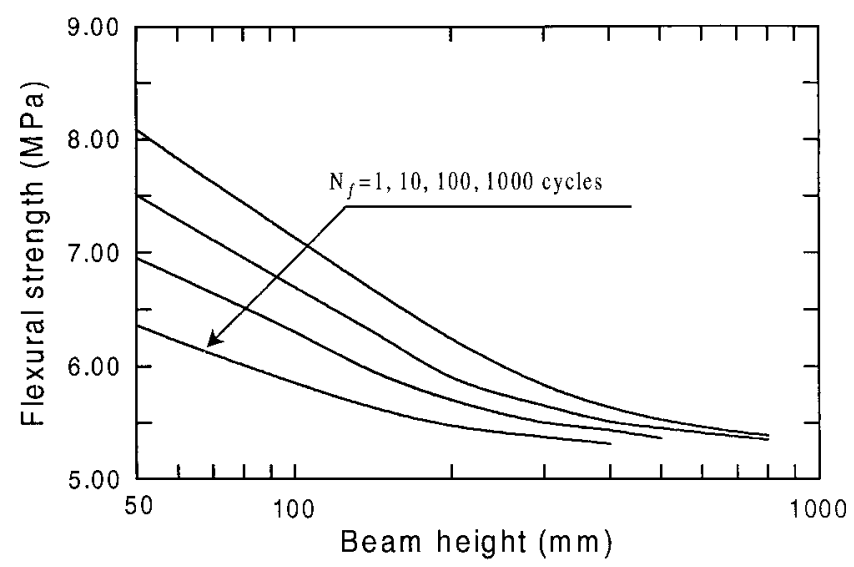

FIG. 10. Size-Effect Law in Fatigue, Showing Some Typical Fatigue Life Requirements

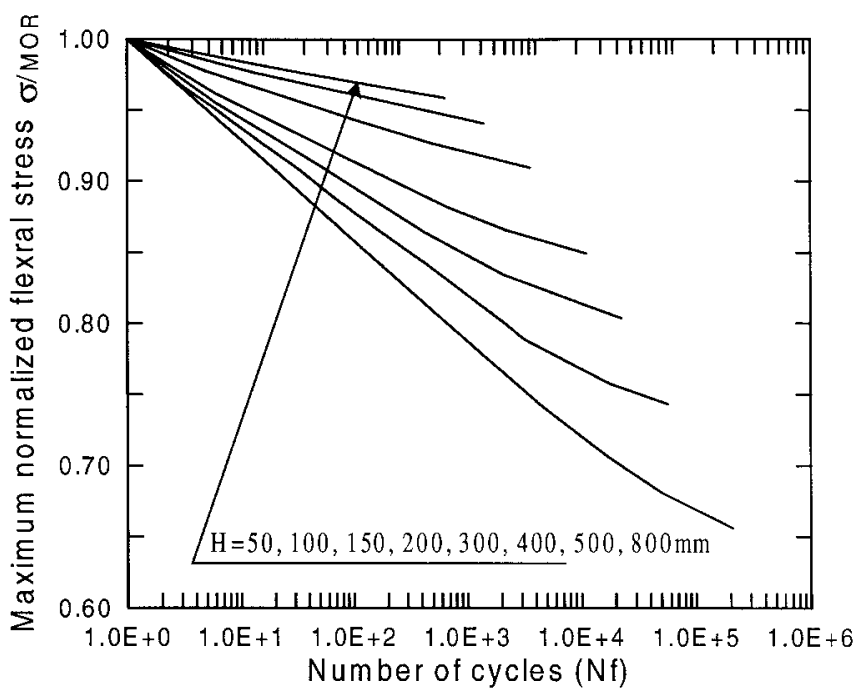

FIG. 11. Relation of Maximum Normalized Flexure Stress with Respect to Monotonic Flexural Strength (MOR) with Fatigue Life, Showing Effect of Beam Size of a different initial crack length and crack openings along the crack even under the same maximum load level (Figs. 6 and 7 ). These differences in crack length and crack openings then led to significant different bridging degradation during cyclic loading between different beam sizes and finally result in different fatigue life.

The monotonic size effect in flexural strength is controlled only by the fictitious crack length and crack openings. However, the size effect on fatigue in bending is controlled by the deformation (crack length and crack openings) and stress degradation along the crack during cyclic loading, which is governed by the cyclic crack bridging law. Fig. 10 shows the numerical results for the size-effect law on fatigue in terms of flexural strength versus beam height curves. From the figure, it can be seen that the shape of the curves are quite different between different fatigue life requirements. So it seems difficult to use a simple expression to describe the size effect in the case of fatigue. Special attention needs to be taken in any design case as far as fatigue life of the structures is concerned.

Note that if the results in Fig. 9 are presented in the form of stress normalized with respect to the flexural strength at monotonic loading (MOR), the conclusion given above will be reversed, as shown in Fig. 11. For a given maximum normalized stress level, the fatigue life for a larger beam is longer than that for a smaller beam. That is because the MOR is size dependent also. So if the beam is designed with the size effect under monotonic loading taken into account, then the beam will also have an enhanced fatigue life, in comparison to that of a smaller beam similarly designed. This implies that beams designed according to size effect law under monotonic loading will also be safe under fatigue loading.

\section{Development of Fatigue Crack}

Typical numerical results for relations between fatigue crack length and number of cycles for different beam sizes, with the same loading condition (i.e., the maximum and minimum flexural stress equal to $5.3 \mathrm{MPa}$ and zero) are shown in Fig. 12. The theoretical simulation successfully reproduced the three experimentally observed stages of crack growth (Stang and Zhang 1994), involving a decelerated stage, steady-state stage, and accelerated stage toward final failure. These three stages are caused by bridging stress degradation within the growing fracture zone in concrete. The crack bridging degradation law controlled the shape of the fatigue crack length versus number of cycles curve. On the other hand, from this figure, it can be seen that fatigue crack growth history as well as the final crack

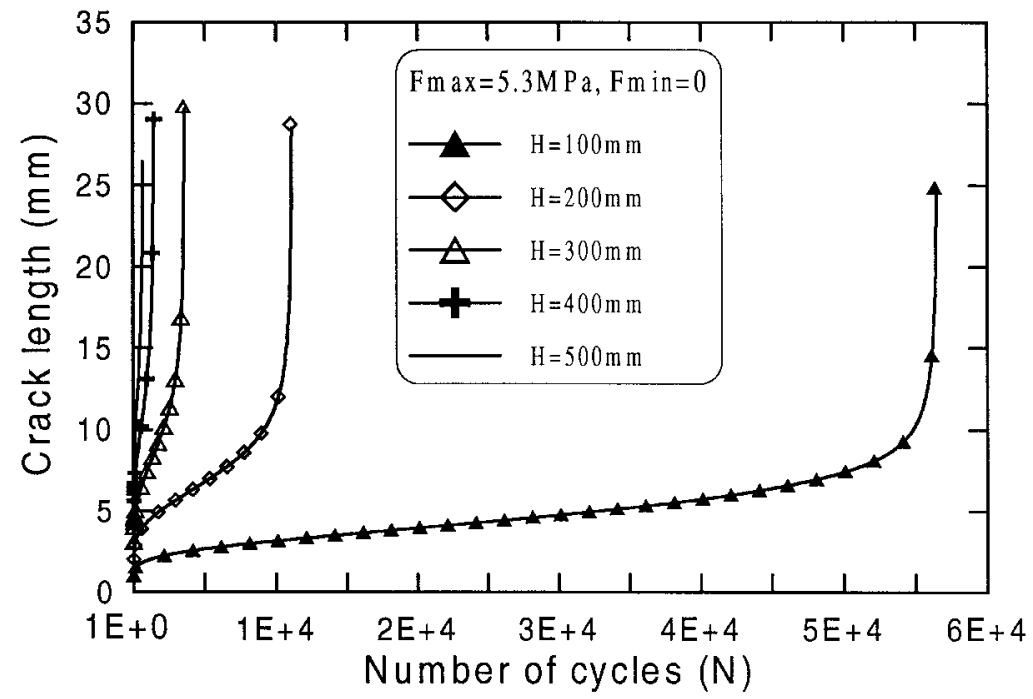

FIG. 12. Relations of Fatigue Crack Length and Number of Cycles, Showing Effect of Beam Size 
length at failure are also dependent on the beam size. The smaller the beam height, the lower is the rate of fatigue crack propagation. The explanation for this observation can still be traced back to the differences in the initial crack length and crack openings, which result in different bridging stress after degradation that led to different crack growth rate.

A general concept in the literature on concrete materials subjected to cyclic loading is that of an envelope curve, which provides a bound for the stress and strain (for compression) values that can be attained under general loading (Otter and Naaman 1988; Kim and Kim 1996). Most authors agree that this envelope coincides with the monotonic loading curve or is at least very close to this curve for plain concrete. This concept may be applicable for fatigue in compression but is questionable for fatigue in flexure or tension. Based on the present investigation, bridging stress degradation exists in the fracture zone. This implies that the toughness of a beam gradually reduces with the number of cycles. Thus, it may be concluded that the CMOD and fatigue crack length at fatigue failure will be less than the values that can be attained under the monotonic case for the same load level, even though further experimental verification is needed to support this conclusion. On the other hand, fatigue failure under bending or tension load will depend not only on the maximum load level but also on the minimum load level because they will affect the bridg-

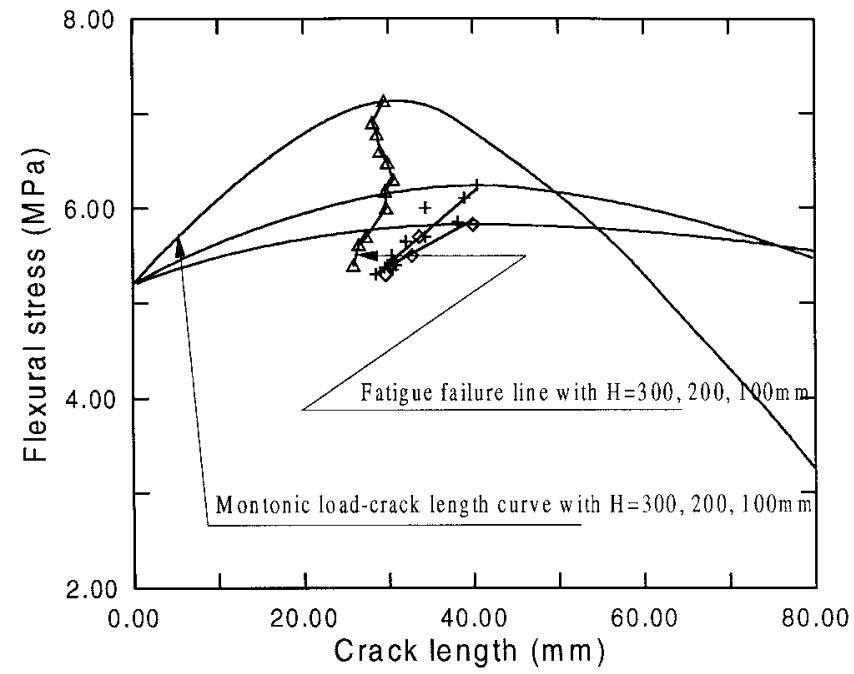

FIG. 13. Effect of Beam Size on Critical Fatigue Crack Length ing degradation simultaneously. The theoretically calculated fatigue failure lines in terms of fatigue crack length under different maximum load levels in the case of minimum load equal to zero for a plain concrete beam with three typical heights $(300,200$, and $100 \mathrm{~mm})$ are presented in Fig. 13. First, one can see that all the fatigue crack lengths at failure, called the critical fatigue crack length for different load levels, are less than the monotonic critical crack length due to the bridging degradation within the fracture zone. With decreasing maximum load, the critical fatigue crack length is smaller and smaller. The critical fatigue crack length is also dependent on the beam size. Second, the lower the load level, the closer the values of the critical fatigue crack length between beams of different sizes. This indicates diminishing size dependence as the maximum cyclic load level decreases.

\section{EXPERIMENTAL VERIFICATION}

To verify the model, a number of fatigue bending tests on plain concrete beams of different beam sizes carried out by Zhang (1998) and Murdock and Kesler (1959) respectively are simulated and analyzed. The specimens and test procedures will be described as follows.

- Fatigue tests carried out by Zhang and Stang (1998a): Zhang carried out some three-point bending fatigue tests on plain concrete beams. In his tests, a rapid hardening cement and natural sand and stone with maximum particle size of 4 and $8 \mathrm{~mm}$, respectively, were used. The concrete proportion by weight was 1:1.62:1.62:0.477 (cement: sand:stone:water). The beams were cured in $23^{\circ} \mathrm{C}$ water for 2 months and then stored in air for another 2 weeks before testing. The compressive and tensile strength after 28 days water curing were 53.2 and $5.20 \mathrm{MPa}$, respectively. The size of the beam is $420 \times 100 \times 100 \mathrm{~mm}$ and the bending span was $400 \mathrm{~mm}$. One stage constant amplitude fatigue loading between maximum and minimum load levels, where the minimum load is equal to zero, was adapted. The tests were carried out in load control using a sinusoidal waveform with a frequency of $4.5 \mathrm{~Hz}$. All the tests were carried out in a $250-\mathrm{kN}$-capacity, $8500 \mathrm{In}$ stron dynamic testing machine.

- Fatigue tests carried out by Murdock and Kesler (1959): Plain concrete specimens, $152.6 \times 152.6 \mathrm{~mm}$ in cross section, were loaded at the one-third points of a 1,524$\mathrm{mm}$ span. Type I portland cement was used in all speci-

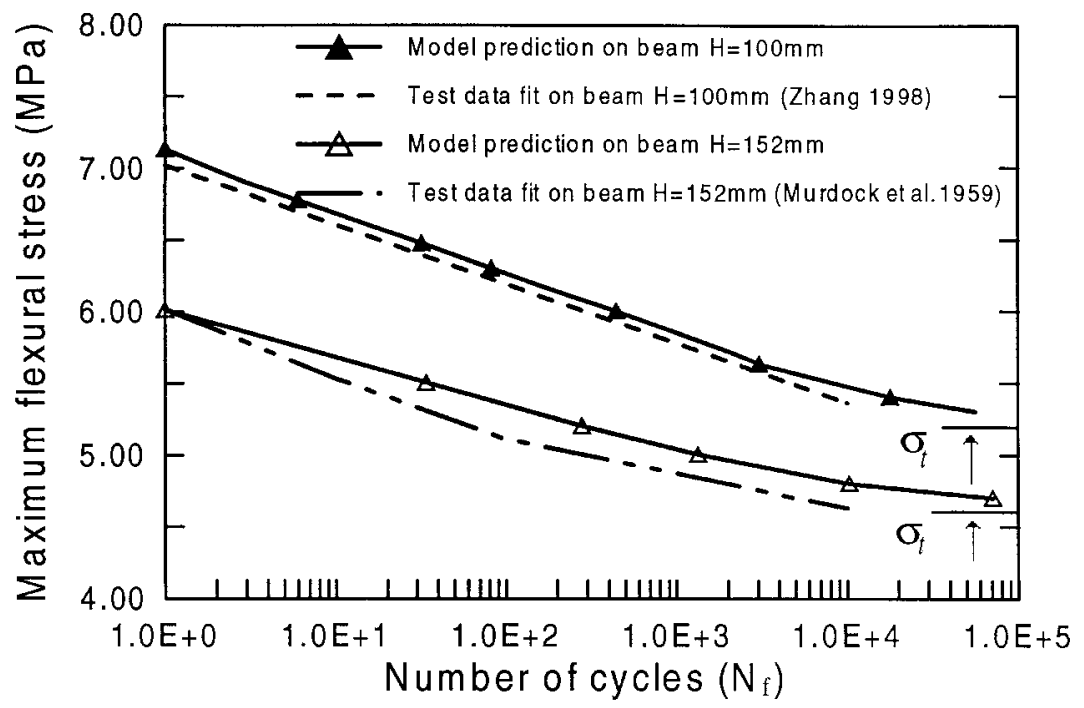

FIG. 14. Comparisons between Model Predictions and Experiments on Size Effect on Flexural Fatigue Expressed in Terms of Maximum Flexural Stress versus Fatigue Life Diagrams 
mens and the fine aggregate was well-graded river sand. The coarse aggregate was river gravel and had a maximum nominal size of $12 \mathrm{~mm}$. The concrete proportion by weight was 1:2.7:3.9:0.52 (cement:sand:gravel:water). The beams were moist cured for 7 days and then stored in a normal laboratory environment. The average compressive strength after 28 days was approximately 31.03 $\mathrm{MPa}$ and the estimated tensile strength was about 4.65 $\mathrm{MPa}$. The age of the specimens at the time of testing ranged from 150 to 300 days. One stage constant amplitude fatigue loading between maximum and minimum load levels was adapted. The tests were carried out in load control with a frequency of 6-7 Hz.

The related material parameters described above, including beam size and load form, as well as the concrete tensile and compressive strength, were applied during numerical calculation using this model. Here, the same crack bridging degradation parameter $d$ was used in both concrete beams. The comparisons between model predictions and experimental results in terms of maximum flexural stress versus fatigue life diagrams are shown in Fig. 14. Quite good agreement between theoretical predictions and test results had been obtained. This model can well capture the characteristics of fatigue in bending regarding the structural size dependence.

\section{CONCLUSIONS}

A semianalytical approach for modeling fatigue performance in flexure of plain concrete that relies on the cyclicstress-crack-width relation as the fundamental constitutive relationship in tension has been presented. The size effect on fatigue in bending is studied by this model. The model results show that the fatigue performance in bending, normally in terms of maximum-stress versus fatigue-life diagram $(S-N)$ is strongly dependent on the structural size. Under the same flexural stress levels, the smaller the beam height, the longer is the fatigue life. However, if the size effect in monotonic bending strength is taken into account (i.e., if the flexural stress is normalized with respect to MOR), the conclusion given above will be reversed. Hence, beams designed with standard sizeeffect law under monotonic loading will also exhibit enhanced fatigue life.

The deformation characteristics, such as fatigue crack growth history as well as the final critical fatigue crack length at fatigue failure, are also dependent on the beam size. At smaller and smaller maximum load levels, the values of the critical fatigue crack length between different beams of different sizes converge, indicating a diminishing size dependency.

The model predictions are compared with the experimental results and good correlation between the model and experiments is found. The model can well capture the characteristics of fatigue crack propagation and give reasonable predictions on fatigue strength and its size-dependent behavior.

To further verify the various model predictions, additional experimental studies on size effect in fatigue are necessary.

\section{ACKNOWLEDGMENT}

This work has been supported by a grant from the National Science Foundation, Washington, D.C., (CMS-9872357) to the University of Michigan.

\section{REFERENCES}

Bazant, Z. P. (1984). "Size effect in blunt fracture: Concrete, rock, metal." J. Engrg. Mech., ASCE, 110(4), 518-535.

Bazant, Z. P. (1987). "Fracture energy of heterogeneous materials and similitude." Fracture of concrete and rock, S. P. Shah and S. E. Swartz, eds., Springer, New York, 229-241.

Bazant, Z. P. (1992). "Size effect and brittleness of structures." Fracture mechanics of concrete structures, Z. P. Bazant, ed., Elsevier Science, New York, 58-67.

Bazant, Z. P., and Xu, K. (1991). "Size effect in fatigue fracture of concrete." ACI Mat. J., 88(4), 390-399.

Bazant, Z. P., and Schell, W. F. (1993). "Fatigue fracture of higher strength concrete and size effect." ACI Mat. J., 90(5), 472-478.

Gopalaratnam, V. S., and Shah, S. P. (1985). "Softening response of plain concrete in direct tension." ACI J., 82(3), 310-323.

Hillerborg, A., Modéer, M., and Petersson, P.-E. (1976). “Analysis of crack formation and crack growth by means of fracture mechanics and finite elements." Cement and Concrete Res., 6, 773-782.

Hordijk, D. A. (1992). "Tensile and tensile fatigue behaviour of concrete, experiments, modelling and analyses." Heron, 37(1), 1-77.

Hsu, T. T. C. (1981). "Fatigue of plain concrete." ACI J., 78(4), 292305.

Kim, J., and Kim, Y. (1996). "Experimental study of the fatigue behavior of high strength concrete." Cement and Concrete Res., 26(10), 15131523.

Li, V. C., Lin, Z., and Matsumoto, T. (1998). "Influence of fiber bridging on structural size-effect." Int. J. Solids and Struct., 35(31-32), 42234238.

Maalej, M., and Li, V. C. (1994). "Flexural strength of fiber cementitious composites." J. Mat. in Civ. Engrg., ASCE, 6(3), 390-406.

Murdock, J. W., and Kesler, C. E. (1959). "Effect of range of stress on fatigue strength of plain concrete beams." ACI J., 55(2), 221-232.

Neville, A. M., and Brooks, J. J. (1987). Concrete technology, Longman Scientific \& Technical, London.

Otter, D. E., and Naaman, A. E. (1988). "Properties of steel fiber reinforced concrete under cyclic loading." ACI Mat. J., 85(4), 254-261.

Paris, P. C., and Erdogan, F. (1963). "A critical analysis of crack propagation laws." J. Basic Engrg., 85, 528-534.

Reinhardt, H. W., Cornelissen, A. W., and Hordijk, D. A. (1986). "Tensile tests and failure analysis of concrete." J. Struct. Engrg., ASCE, 112(11), 2462-2477.

Stang, H. (1992). "Evaluation of properties of cementitious materials." Proc., Int. RILEM/ACI Workshop, High Performance Fiber Reinforced Cement Compos., H. W. Reinhardt and A. E. Naaman, eds., Chapman and Hall, London, 388-406.

Stang, H., and Zhang, J. (1994). "Experimental determination of fatigue crack growth in fibre reinforced concrete." Recent advances in experimental mechanics, J. F. Silva Gomez, ed., Balkema, Rotterdam, The Netherlands, 1347-1352.

Tada, H. (1985). The stress analysis of cracks handbook, Paris Prod. Inc., Louis, Mo.

Tepfers, R. (1979). "Tensile fatigue strength of plain concrete." ACI J., 76(5), 919-993.

Tepfers, R., and Kutti, T. (1979). "Fatigue strength of plain, ordinary and lightweight concrete.” ACI J., 76(8), 636-652.

Ulfkjær, J. P., Krenk, S., and Brincker, R. (1995). “Analytical model for fictitious crack propagation in concrete beams." J. Engrg. Mech., ASCE, 121(1), 7-15.

Zhang, B., and Phillips, D. V. (1989). "Fatigue life of plain concrete under stress reversal." Proc., Int. Conf. on Recent Devel. in Fracture of Concrete and Rock, S. P. Shah, S. E. Swartz, and B. Barr, eds., Elsevier Applied Science, London, 183-192.

Zhang, J., and Stang, H. (1998a). "Fatigue performance in flexure of fiber reinforced concrete." ACI Mat. J., 95(1), 58-67.

Zhang, J., and Stang, H. (1998b). "Application of stress crack width relationship in predicting the flexural behavior of fiber reinforced concrete." Cement and Concrete Res., 28(3), 439-452.

Zhang, J., Stang, H., and Li, V. C. (1999). "Fatigue life prediction of fiber reinforced concrete under flexure load." Int. J. Fatigue, 21(10), 1033-1049.

Zhang, J., Stang, H., and Li, V. C. (2000). "Experimental study on crack bridging in FRC under uniaxial fatigue tension." J. Mat. in Civ. Engrg., ASCE, 12(1), 66-73. 